\title{
In-house polymerase chain reaction for affordable and sustainable Chlamydia trachomatis detection in Trinidad and Tobago
}

\author{
Joanne Rampersad, ${ }^{1,5}$ Xiaohui Wang, ${ }^{2}$ Helen Gayadeen, ${ }^{3}$ \\ Samuel Ramsewak, ${ }^{3}$ and David Ammons ${ }^{4}$
}

Suggested citation Rampersad J, Wang X, Gayadeen H, Ramsewak S, Ammons D. In-house polymerase chain reaction for affordable and sustainable Chlamydia trachomatis detection in Trinidad and Tobago. Rev Panam Salud Publica. 2007;22(5):317-22.

\begin{abstract}
Objectives. To provide a preliminary assessment of in-house polymerase chain reaction (PCR) as an alternative to the more costly commercial test for detection of asymptomatic infection by Chlamydia trachomatis and to provide much needed demographic data on infection indicators within the Trinidad and Tobago public health care system.

Methods. An inexpensive in-house nested-PCR with an Internal Amplification Control was used to detect $\mathrm{C}$. trachomatis and Neisseria gonorrhoeae in urine samples collected from 273 apparently healthy, pregnant women from March-September 2004 in Trinidad, West Indies. Demographic information on participants was collected and subjected to statistical analyses.

Results. C. trachomatis was detected in 57/273 (21\%) samples, of which $5(2 \%)$ were also positive for $\mathrm{N}$. gonorrhoeae. Infection correlated well with certain demographic parameters, with the highest incidence of $\mathrm{C}$. trachomatis infection found among pregnant women that were single or of African descent.

Conclusions. Given the lack of commercial tests in Trinidad, in-house PCR is an inexpensive alternative that can be used to detect asymptomatic infections of $\mathrm{C}$. trachomatis and to provide demographic information needed for interventions by the public health care system.
\end{abstract}

Key words Chlamydia trachomatis, polymerase chain reaction, Trinidad and Tobago.

Department of Life Sciences, University of the West Indies, St. Augustine, Trinidad and Tobago. Mathematics Department, University of TexasPan American, Edinburg, Texas, United States of America.

Faculty of Medical Sciences, School of Medicine, University of the West Indies, Mount Hope, Trinidad and Tobago.

4 Faculty of Medical Sciences, School of Veterinary Medicine, University of the West Indies, Mount Hope, Trinidad and Tobago.

5 Chemistry Department, University of Texas-Pan American, Edinburg, Texas, United States of America. Send correspondence to: David Ammons, ica. Send correspondence to: David Ammons,
Chemistry Department, University of Texas-Pan American, 1201 West University Drive, Edinburg, Texas, 78539, United States of America; telephone: 956-381-2097; fax: 956-384-5006; e-mail: ammonstt@ hotmail.com.
Chlamydia trachomatis and Neisseria gonorrhoeae are sexually transmitted bacteria known to cause a range of diseases in both men and women, with women being at particular risk of serious complications $(1,2)$. Neonates infected at birth by their mothers can suffer from ailments such as pneumonia and conjunctivitis $(3,4)$. Most importantly, both bacteria are capable of establishing subclinical infections whereby unsuspecting carriers can pass on the infection through sexual contact. Testing has been shown effective for the identification of infected, asymptomatic individuals (5) and economic gains by the health care system have been attributed to testing (6). Testing is recommended by the Centers for Disease Control and Prevention (CDC, Atlanta, Georgia, United States of America) (7). Commercial diagnostic systems, based on nucleic acid amplification, have been developed to serve this need and are now considered to be the preferred method 
(7). However, these systems are expensive, though efforts have been made to reduce their cost (8). For the Republic of Trinidad and Tobago, and other countries in the developing world where resources are relatively limited, the cost to purchase, use, and maintain these commercial diagnostic systems can be prohibitive.

Studies have indicated that C. trachomatis infection may represent a serious health threat to the Trinidadian population (9). It is also an important factor in pregnancy and fertility-related problems in Trinidad (10). However, despite the need for testing (11), to date, C. trachomatis screening has not been made available by the Government's health care system. Recognizing the importance of and need for C. trachomatis screening and the prohibitive cost of commercial systems, the Diagnostic Laboratory Services at the Government's Mt. Hope Hospital, in collaboration with the University of the West Indies, undertook a preliminary study. The study would determine if a less expensive, in-house diagnostic test could serve the health care needs of the nation by achieving two desired objectives: the detection of asymptomatic infections and the collection of demographic information needed for intervention by the public health care system.

\section{MATERIALS AND METHODS}

The ethics committees of the Faculty of Medical Sciences of the University of the West Indies and the General Hospital in Port-of-Spain, Trinidad and Tobago, approved this study. Administrative approval was obtained from the Principal Medical Officer, Ministry of Health, Government of Trinidad.

\section{Sample collection and processing}

Samples were collected in MarchSeptember 2004 from 273 apparently healthy, pregnant women at private as well as government clinics. Any and all pregnant women present in the respective clinics at the time of sampling were invited to participate. A 15-20
$\mathrm{mL}$ sample of first-void urine was collected, held at $4^{\circ} \mathrm{C}$ until transported (within 24 hours of collection), and stored at $-20^{\circ} \mathrm{C}$ until DNA was prepared from the sample (within two months). DNA from both urine and vulvular swabs was prepared using Chelex 100 resin (Sigma Chemical Co., St. Louis, United States) according to Jurstrand (12).

\section{Polymerase chain reaction (PCR)}

Primary and nested multiplex-PCR reactions were optimized by testing $1.5,2$, and $3 \mathrm{mM} \mathrm{MgCl}_{2}$ in the reaction, each at 12 temperatures ranging from $45^{\circ} \mathrm{C}-65^{\circ} \mathrm{C}$ using a Gradient Master Cycler (Eppendorf Inc., Westbury, New York, United States). Primers utilized in this work are presented in Table 1 and target the cryptic plasmids in C. trachomatis (for example, GenBank X06707) or N. gonorrhoeae (for example, GenBank M10316). In order to minimize contamination, four separate rooms were used; one for creating the PCR reaction mix, a second for template preparation and primary PCR, a third for performing nested reactions, and a fourth for gel electrophoresis. Nested reactions were performed in a biosafety hood where $1 \mathrm{~mL}$ of primary reaction was delivered to a nested tube with a $1 \mathrm{~mL}$ platinum urine loop. The end of the loop was then washed briefly in a $10 \%$ bleach solution, rinsed in water, and flamed before reusing. Amplification products from $15 \mathrm{~mL}$ of the PCR reaction were separated on a $2 \%$ agarose gel, stained with ethidium bromide, and visualized under a $302 \mathrm{~nm}$ ultraviolet light. DNA markers were created by PCR amplification of virulence genes from $E$. coli generating calculated-sized base pair (bp) fragments of $881,520,337,274$, and 171 , and their relative sizes confirmed using a commercial DNA size standard (100 bp ladder, Promega Corp., Madison, Wisconsin, United States).

Primary reactions contained $0.2 \mathrm{mM}$ each dNTP, reaction buffer with $\mathrm{MgCl}_{2}$ at $3 \mathrm{mM}, 0.5$ pmoles/mL each of primers HO1, HO3, Chlam5 (5'-CATTATGTCGGAGTCTGAGC), and Chlam3 (5'-GGATGACTCAAGGAATAGTCG), $1 \mathrm{~mL}$ of Internal Amplification Control (IAC) template (a DNA amplicon randomly amplified from the genome of a chicken with primer IAC whose concentration was undetermined), 0.4 pmoles $/ \mathrm{mL}$ primer IAC (5'-TGTTTGACAGCTTATCAT), $5 \mathrm{~mL}$ DNA template preparation, 0.5 units of Taq polymerase, and water to $25 \mathrm{~mL}$. Amplification conditions were $94^{\circ} \mathrm{C}$ for 15 seconds, $60^{\circ} \mathrm{C}$ for 30 seconds, $72^{\circ} \mathrm{C}$ for 60 seconds, for 40 cycles.

Nested reactions contained $0.2 \mathrm{mM}$ each dNTP, reaction buffer containing $\mathrm{MgCl}_{2}$ at $2 \mathrm{mM}, 0.5$ pmoles $/ \mathrm{mL}$ each of primers KL-1, KL-2, Gon5 (5'-GTTCTTGACGCTCCATATCG) and Gon3 (5'-ACGAGGCATTGAAGCAAAGC), 0.4 pmoles $/ \mathrm{mL}$ IAC, $1 \mathrm{~mL}$ of the primary reaction, 0.5 units of Taq polymerase, and water to $25 \mathrm{~mL}$. Amplification conditions were $94^{\circ} \mathrm{C}$ for 15 seconds, $58.5^{\circ} \mathrm{C}$ for 30 seconds, $72^{\circ} \mathrm{C}$ for 30 seconds, for 40 cycles.

TABLE 1. Summary information on polymerase chain reaction (PCR) primers used in this study

\begin{tabular}{lcccc}
\hline Reaction & Primer pair & Target organism & Size product (bp) & Reference \\
\hline Primary & HO1/HO3 & Neisseria gonorrhoeae & 390 & $(13)$ \\
& Chlam5/Clam3 & Chlamydia trachomatis & 526 & This work \\
Nested & KL1/KL2 & Chlamydia trachomatis & 240 & $(14)$ \\
& Gon5/Gon3 & Neisseria gonorrhoeae & 150 & This work \\
Both & Random fragment from & $\sim 900$ & This work \\
& IAC & the chicken genome & & \\
\hline
\end{tabular}

${ }^{\mathrm{a}}$ Both $=$ used in both primary and nested reactions. 


\section{DNA sequencing}

DNA sequence was determined for C. trachomatis and N. gonorrhoeae from amplicons generated in the nested reaction. Amplification products were electrophoresed through a $1 \%$ agarose gel, and the agar containing the amplified DNA was then cut from the gel, briefly frozen, thawed, and spun at $12000 \mathrm{rpm}$ through a polypropylene fiber to remove the DNA-containing liquid. Lastly it was ethanol precipitated. An ABI Big Dye (Applied Biosystems Group, Foster City, California, United States) sequencing kit was used according to the manufacturer's instructions, using the nested primers individually in separate reactions, and the reactions resolved on an ABI377 DNA sequencing machine.

\section{Digene's Hybrid Capture II CT-ID}

DNA from 10 swabs and 10 urine samples were sent to the Barbados Reference Laboratory for C. trachomatis testing using Digene's Hybrid Capture II CT-ID test (Digene Corp., Gaithersburg, Maryland, United States). Samples shown by PCR to be either positive or negative for C. trachomatis were chosen for analysis.

\section{Statistical analysis}

Statistical analyses were performed using the Statistical Package for the Social Sciences, version 15.0 (SPSS Inc., Chicago, Illinois, United States), and $\mathrm{R}$ for Windows (The R Foundation, Vienna, Austria) (15). The Chi-square test was used to assess the association of pairs of categorical variables. Multidimensional log-linear analyses were used to analyze a three-way contingency table consisting of marital status, ethnicity, and infection status. Because the log-linear models indicated that a three-way interaction effect of marital status, ethnicity, and infection status was not significant, analyses of two-way contingency tables were performed. A significance level of 0.05 was used throughout the analyses.

\section{RESULTS}

The in-house test provided clear and easy to interpret results (Figure 1). Of 273 urine samples from apparently healthy, pregnant women, the primary PCR detected C. trachomatis in 21 samples and both $C$. trachomatis and $N$. gonorrhoeae in 1 sample. The nested PCR detected C. trachomatis in a total of 57 samples, 5 of which also contained N. gonorrhoeae. None of the samples contained $N$. gonorrhoeae without a $C$. trachomatis co-infection.

As expected, all samples that tested positive in the primary reaction for either bacterium were also positive for the same bacterium in the more sensitive, nested reaction. DNA sequence analysis of amplicons generated in the nested reaction for both a positive C. trachomatis sample (GenBank DQ005492), and a positive N. gonorrhoeae sample, (GenBank DQ005493), confirmed the origin of amplified DNAs.

Results using the in-house test compared well with results obtained by

FIGURE 1. An example of test results for both primary and nested PCR reactions ${ }^{\mathrm{a}}$

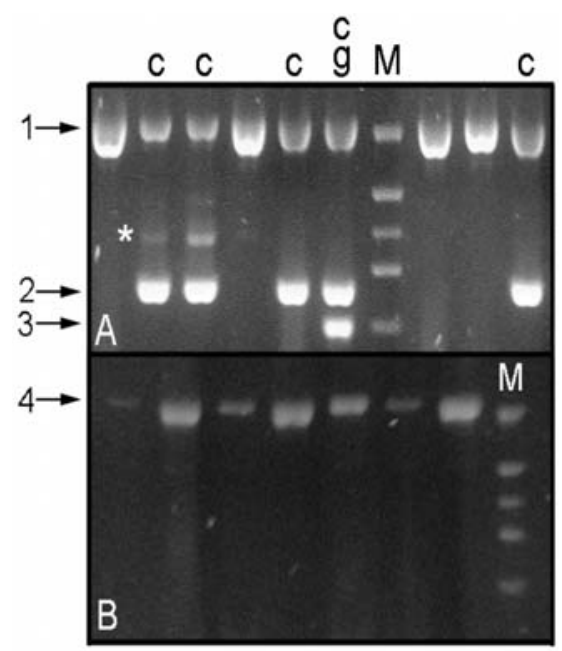

a Panels $A \& B=$ nested and primary reactions respectively on a $2 \%$ agarose gel; Arrow $1 \& 4=$ internal amplification control; arrow $2=C$. trachomatis; arrow $3=N$. gonorrhoeae; $\mathrm{C}=C$. trachomatis positive; $\mathrm{g}=N$. gonorrhoeae positive; $\mathrm{M}=\mathrm{DNA}$ size standards (bp). $881,520,337,274$ $171 ;{ }^{*}=$ non-specific amplification products seen in some $171 ; *=$ non-specific amplification products
of the nested reactions that were ignored. the Barbados Reference Laboratory using Digene's Hybrid Capture II CTID (Table 2). In all instances, where the commercial test was either positive or equivocal, the in-house test was positive; however, two samples, negative by the commercial test, were positive by the in-house test. These two samples were tested twice by the in-house test, and both times the results were positive in both the primary and nested reactions.

The association of four demographic parameters with $C$. trachomatis infection is presented in Table 3. A statistically significant association was not observed between either trimester and infection status $(P=0.462)$, nor the type of health facility and infection status $(P=0.104)$. Therefore, the probability of being either positive $(79.1 \%)$ or negative $(20.9 \%)$ was estimated with $95 \%$ confidence levels (Table 3 ), regardless of the trimester and facility subgroups. Alternatively, the associations between both marital status and ethnicity and the infection status were very strong, indicated by extremely small $P$ values (near zero). Infection probability and 95\% confidence intervals for each subgroup of ethnicity and marital status are also given in Table 3.

\section{DISCUSSION}

Although routine testing for C. trachomatis has never been available within the public health care system in Trinidad and Tobago, studies have indicated both a high rate of exposure to the organism (9) and its involvement in disease within the Trinidadian population (10). The need for routine testing for C. trachomatis in Trinidad has been reported (11) and numerous reports can be found in the literature on the use of commercial tests for the detection of C. trachomatis (16-18). However, for developing countries like Trinidad and Tobago, these reports are of little use since the tests described are prohibitively expensive. Therefore, an economical alternative to commercial tests was sought for use within the Trinidad and Tobago health care system. 
TABLE 2. Comparison of in-house and commercial tests, Trinidad and Tobago, 2004

\begin{tabular}{|c|c|c|}
\hline Patient No. & $\begin{array}{l}\text { Digene's Hybrid } \\
\text { Capture II CT-ID }\end{array}$ & In-house multiplex \\
\hline 43 & $\mathrm{~S}^{\mathrm{a}, \mathrm{b}}$ & $\mathrm{S}^{\mathrm{c}}$ \\
\hline 23 & $\mathrm{~S}^{\mathrm{c}}$ & $\mathrm{S}^{\mathrm{c}}$ \\
\hline 147 & $\mathrm{~S}^{\mathrm{c}}$ & $\mathrm{S}^{\mathrm{c}}$ \\
\hline 224 & $S^{c}$ & $\mathrm{~S}^{\mathrm{c}}$ \\
\hline 191 & $S$ & $\mathrm{~S}^{\mathrm{c}}$ \\
\hline 141 & $\mathrm{~S}$ & $\mathrm{~S}$ \\
\hline 41 & $S$ & $S$ \\
\hline 81 & $S$ & $\mathrm{~S}$ \\
\hline 242 & $\mathrm{~S}$ & $\mathrm{~S}$ \\
\hline 252 & $\mathrm{~S}$ & $\mathrm{~S}$ \\
\hline 196 & $U^{d, b}$ & $U^{c}$ \\
\hline 274 & $U^{b}$ & $U^{c}$ \\
\hline 138 & $U^{c}$ & $U^{d}$ \\
\hline 144 & U & $U^{c}$ \\
\hline 73 & $U$ & $U$ \\
\hline 86 & $U$ & U \\
\hline 107 & U & $U$ \\
\hline 183 & $U$ & U \\
\hline 186 & $U$ & $U$ \\
\hline 198 & U & $U$ \\
\hline \multicolumn{3}{|c|}{$\begin{array}{l}\text { a } S=\text { swab. } \\
\text { b } U=\text { urine. } \\
\text { c Chlamydia trachomatis. } \\
{ }^{\text {d } C h l a m y d i a ~ t r a c h o m a t i s ~ a n d ~ N e i s s e r i a ~ g o n o r r h o e a e . ~} \\
\text { e Equivocal result. }\end{array}$} \\
\hline
\end{tabular}

TABLE 3. Association of trimester of pregnancy, marital status, facility, and ethnicity with Chlamydia trachomatis infection, Trinidad and Tobago, 2004

\begin{tabular}{|c|c|c|c|}
\hline & \multicolumn{2}{|c|}{ Infection status } & \multirow[b]{2}{*}{$\begin{array}{c}\text { Row total } \\
273\end{array}$} \\
\hline & $\begin{array}{c}\text { Negative (216: 79.1\%) } \\
\mathrm{Cl}^{\mathrm{a}}(74.3 \%, 83.9 \%)\end{array}$ & $\begin{array}{c}\text { Positive (57: } 20.9 \%) \\
\text { Cl (16.1\%, } 25.7 \%)\end{array}$ & \\
\hline \multicolumn{4}{|c|}{ Trimester of pregnancy } \\
\hline 1st trimester & 27 & 4 & 31 \\
\hline 2nd trimester & 74 & 19 & 93 \\
\hline 3rd trimester & 115 & 34 & 149 \\
\hline \multicolumn{4}{|l|}{ Facility $^{b}$} \\
\hline Private & 52 & 8 & 60 \\
\hline Public ${ }^{\mathrm{C}}$ & 164 & 49 & 213 \\
\hline \multicolumn{4}{|l|}{ Marital Status } \\
\hline \multirow[t]{2}{*}{ Married } & $84(91.3 \%)$ & $8(8.7 \%)$ & \\
\hline & $\mathrm{Cl}(85.5 \%, 97.1 \%)$ & $\mathrm{Cl}(2.9 \%, 14.5 \%)$ & 92 \\
\hline \multirow[t]{2}{*}{ Common law } & $76(80.9 \%)$ & $18(19.1 \%)$ & \\
\hline & $\mathrm{Cl}(73.0 \%, 88.8 \%)$ & $\mathrm{Cl}(11.2 \%, 27.0 \%)$ & 94 \\
\hline \multirow[t]{2}{*}{ Single } & $56(64.4 \%)$ & $31(35.6 \%)$ & \\
\hline & $\mathrm{Cl}(54.3 \%, 74.5 \%)$ & $\mathrm{Cl}(25.2 \%, 45.7 \%)$ & 87 \\
\hline \multicolumn{4}{|l|}{ Ethnicity } \\
\hline \multirow[t]{2}{*}{ African } & $71(68.3 \%)$ & $33(31.7 \%)$ & \\
\hline & $\mathrm{Cl}(59,3 \%, 77.2 \%)$ & $\mathrm{Cl}(22.8 \%, 40.7 \%)$ & 104 \\
\hline \multirow[t]{2}{*}{ East Indian } & $64(92.8 \%)$ & $5(7.2 \%)$ & \\
\hline & $\mathrm{Cl}(86.6 \%, 98.9 \%)$ & $\mathrm{Cl}(1.1 \%, 13.4 \%)$ & 69 \\
\hline \multirow[t]{2}{*}{ Mixede } & $81(81.0 \%)$ & $19(19.0 \%)$ & \\
\hline & $\mathrm{Cl}(73.3 \%, 88.7 \%)$ & $\mathrm{Cl}(11.3 \%, 26.7 \%)$ & 100 \\
\hline
\end{tabular}

The first objective of this study was to determine if an in-house, PCR could detect subclinical infection in individuals. This was necessary for purposes of routine testing and treatment. The decision was made to use a nestedPCR because it is known to be highly sensitive. In fact, one potential concern was the false-positive results that the nested PCR might produce due to its high sensitivity. However, in this study, positive samples were nonrandom regarding both race and marital status (Table 2), and thus consistent with few or no false-positive reactions from random contamination. Attesting to the sensitivity of a nested-PCR, it detected approximately 2.5 times more infected samples from asymptomatic individuals than did the primary PCR. The nested PCR also performed well compared to Digene's Capture Hybrid II CT-ID, used by the Barbados Reference Laboratory for the detection of Chlamydia (Table 2). Although financial constraints limited the sample size $(n=20)$, results suggested that the commercial test had no obvious advantage over the in-house test (Table 2 ). The two samples positive by the inhouse test and negative with the commercial test were tested twice, both times giving positive reactions for $C$. trachomatis in both the primary and nested reactions. These results suggest that the two samples contained the bacterium and that the reactions using Digene's Capture Hybrid II CT-ID may have been falsely negative (19). False-negatives are, in fact, a recognized problem with PCR tests, and internal amplification controls, such as the one incorporated in the in-house test, have been recommended (20).

Although the in-house test utilized in this study was primarily for the detection of C. trachomatis, N. gonorrhoeae was included, as in commercial systems, due to its importance as an STD. However, unlike $C$. trachomatis, the culture and diagnosis of $N$. gonorrhoeae are available within the public health care system of Trinidad and Tobago; its inclusion in this preliminary study was mainly in anticipation of the future development of the test and not a focus of this study. 
Because routine screening for C. trachomatis has never been available in Trinidad and Tobago, the second objective of this study was to determine if the test could provide the health authorities in Trinidad and Tobago with much needed data on infection demographics. In this regard, the test performed well identifying non-random infection within the population and indicating that marital status and ethnicity may serve as indicators of infection; that is, pregnant women who are single and/or of African/mixedAfrican descent may have a higher probability of C. trachomatis infection (Table 3). Aside from health consequences to the mother, these results indicate that a relatively large number of infants of African descent are being born from infected mothers-with unknown consequences to the child. Although infection status may seem higher among women at public health facilities, a significant association between infection and facility type was not observed using a significance level of 0.05 . However, the $P$ value of 0.104 was marginal, indicating that C. trachomatis infection may be more prevalent among patients at public health facilities and should be examined further as a potential indicator of infection status.

Because Trinidad and Tobago has not been able to afford commercial tests for routine detection of C. trachomatis, the government health care system has not been able to provide this basic service to clients. Although in-house PCR tests may not be as rigorously characterized as commercial tests, the nested PCR has been shown useful in Trinidad for the detection of sub-clinical infection and for identifying demographic parameters indica- tive of higher infection rates. With a calculated cost in reagents of less than US\$ 1.50 per test, in Trinidad and Tobago, and perhaps other countries with similar challenges, in-house PCR tests may represent a useful tool for the detection and control of C. trachomatis infection.

Acknowledgements. We thank the University of the West Indies' Research and Publication Fund Committee for financial support of this work and the Barbados Reference Laboratory for assistance in analyzing samples with Digene's Hybrid Capture II CT-ID. JR and DA thank the Wellness Project for its support. Xiaohui Wang's research is partially supported by a 2006-2007 Faculty Development Council Award from the University of Texas-Pan American.

\section{REFERENCES}

1. Hillis SD, Owens LM, Marchbanks PA, Amsterdam LF, MacKenzie WR. Recurrent chlamydial infections increase the risks of hospitalization for ectopic pregnancy and pelvic inflammatory disease. Am J Obstet Gynecol. 1997;176:103-7.

2. Westrom L, Joesoef R, Reynolds G, Hadgu, A, Thompson SE. Pelvic inflammatory disease and fertility. a cohort study of 1,844 women with laparoscopically verified disease and 657 control women with normal laparoscopy results. Sex Transm Dis. 1992;19: 185-92.

3. Numazaki K, Wainberg MA, McDonald J. Chlamydia trachomatis infections in infants. CMAJ 1989;140: 615-22.

4. Numazaki K, Asanuma H, Niida Y. Chlamydia trachomatis infection in early neonatal period. BMC Infect Dis. 2003;3:2.

5. Sherrard J, Rings M, Hall C. Where has all the chlamydia come from? The clinical impact of the introduction of an improved Chlamydia test. Int J STD AIDS 2005;16:163-5.

6. Hu D, Hook EW 3rd, Goldie SJ. Screening for Chlamydia trachomatis in women 15 to 29 years of age: a cost-effectiveness analysis. Ann Intern Med. 2004;141:501-13.

7. Centers for Disease Control and Prevention. Sexually transmitted diseases treatment guidelines 2002; MMWR. 251(No. RR6).2-34.

8. Currie MJ, McNiven M, Yee T, Schiemer U, Bowden FJ. Pooling of Clinical Specimens Prior to Testing for Chlamydia trachomatis. J Clin Microbiol. 2004;42:4866-7.
9. Eley A, Hemeg H A, Geary I, Ramsewak S, Herring A, Caul EO. Prevalence of Chlamydia trachomatis $\operatorname{IgG}$ antibodies in antenatal patients from Trinidad. Sex. Transm. Inf. 2001;77:30-302.

10. Barlow REL, Cooke ID, Odukoya O, et al. The prevalence of Chlamydia trachomatis in fresh tissue specimens from patients with ectopic pregnancy or tubal factor infertility as determined by PCR and insitu hybridization. J. Med. Microbiol. 2001;50:902-8.

11. Swanston WH, Prabhakar P, Barrow L, Mahabir BS, Furlonge C. Single dose (direct observed) azithromycin therapy for Neisseria gonorrhoeae and Chlamydia trachomatis in STD clinic attenders with genital discharge in Trinidad and Tobago. West Indian Med J. 2001;50:198-202.

12. Jurstrand M, Falk L, Fredlund H, et al. Characterization of Chlamydia trachomatis omp1 genotypes among sexually transmitted disease patients in Sweden. J Clin Microbiol. 2001;39: 3915-9.

13. Ho BS, Feng WG, Wong BK, Egglestone SI. Polymerase chain reaction for the detection of Neisseria gonorrhoeae in clinical samples. J Clin Pathol. 1992;45:439-42.

14. Mahony JB, Luinstra KE, Sellors JW, Jang D, Chernesky MA. Confirmatory polymerase chain reaction testing for Chlamydia trachomatis in first-void urine from asymptomatic and symptomatic men. J Clin Microbiol. 1992;30: 2241-5.

15. R Development Core Team. R: a language and environment for statistical computing. $\mathrm{R}$
Foundation for Statistical Computing: Vienna, Austria. Available from: www.R-project.org. Accessed on: 12 December 2006.

16. Leslie DE, Azzato F, Ryan N, Fyfe J. An assessment of the Roche Amplicor Chlamydia trachomatis/Neisseria gonorrhoeae multiplex PCR assay in routine diagnostic use on a variety of specimen types. Commun Dis Intell. 2003;27:373-9.

17. Moncada J, Schachter J, Hook EW 3rd, et al. The effect of urine testing in evaluations of the sensitivity of the Gen-Probe Aptima Combo 2 assay on endocervical swabs for Chlamydia trachomatis and Neisseria gonorrhoeae: the infected patient standard reduces sensitivity of single site evaluation. Sex Transm Dis. 2004; 31:273-7.

18. Bang D, Angelso L, Schirakow B, Westh H. Comparison of the Becton Dickinson strand displacement amplification and Cobas Amplicor Roche PCR for the detection of Chlamydia trachomatis: pooling versus individual tests. Clin Microbiol Infect. 2003;9:1020-3.

19. Girdner JL, Cullen AP, Salama TG, He L, Lorincz A, Quinn TC. Evaluation of the Digene Hybrid Capture II CT-ID test for detection of Chlamydia trachomatis in Endocervical Specimens. J Clin Microbiol. 1999;37:1579-81.

20. Hoofar J, Cook N, Malorny, et al. Making internal amplification control mandatory for diagnostic PCR. J Clin Microbiol. 2003;4:5835.

Manuscript received on 7 July 2006. Revised version accepted for publication on 3 October 2007. 
RESUMEN Objetivos. Hacer una evaluación preliminar de un sistema autóctono para la detección de la infección asintomática por Chlamydia trachomatis mediante la reacción en cadena de la polimerasa (RCP), como alternativa a los costosos sistemas comerciales, y ofrecer datos demográficos muy necesarios relacionados con los indicadores de esta infección en el sistema de salud pública de Trinidad y Tobago.

Sistema autóctono para la detección asequible y sustentable de Chlamydia trachomatis por la reacción en cadena de la polimerasa en Trinidad y Tobago interno de la amplificación para la detección de C. trachomatis y Neisseria gonorrhoeae en muestras de orina de 273 mujeres embarazadas asintomáticas, entre marzo y septiembre de 2004 en Trinidad y Tobago, Indias Occidentales. Se obtuvo la información demográfica de las participantes y se sometió a análisis estadístico.

Resultados. Se detectó C. trachomatis en 57/273 (21\%) muestras, de las cuales 5 (2\%) fueron también positivas para $N$. gonorrhoeae. La infección se correlacionó bien con algunos parámetros demográficos; la mayor incidencia de la infección por C. trachomatis se observó en las mujeres embarazadas solteras o de ascendencia africana.

Conclusiones. Debido al déficit de sistemas de diagnóstico comerciales en Trinidad, la RCP autóctona es una alternativa económica que puede emplearse para detectar la infección asintomática por C. trachomatis y obtener la información demográfica necesaria para que el sistema de salud pública implemente intervenciones.

Palabras clave 